\title{
HYDROCYCLONE FOR PRE-FILTERING OF IRRIGATION WATER
}

\author{
Olívio José Soccol ${ }^{1}$; Tarlei Arriel Botrel2* \\ ${ }^{1}$ UDESC/CAV - Depto. de Engenharia Rural, C.P 281 - 88520-000 - Lages, SC - Brasil. \\ ${ }^{2}$ USP/ESALQ - Depto. de Engenharia Rural, C.P 09 - 13418-900 - Piracicaba, SP - Brasil. \\ *Corresponding author <tabotrel@esalq.usp.br>
}

\begin{abstract}
The use of water containing suspended sediments causes serious problems to irrigation systems. Choosing the right filtering system type and capacity is essential to avoid increases in operational and maintenance costs of irrigation resulting from the need for cleaning and frequent component replacing. Prefilters, such as the hydrocyclone, are important for their significant capability of retaining particles suspended in the water. Data on hydrocyclones performance for pre-filtering of irrigation water can be found in the literature, but research data in Brazil are scarce. Therefore, four Rietema type hydrocyclones (50 mm diameter) were constructed, one with circular-end and the other three presenting rectangular-end feeding tubes. The evaluation of hydrocyclones performance was conducted by using suspensions of fine sand and clay soil particles under varied pressure differentials. The comparison criteria were the discharge and the separation capability, given by total efficiency and reduced total efficiency. The hydrocyclone with circular-end feeding tube presented the highest indexes for the adopted criteria, considering sand and soil suspensions.
\end{abstract}

Key words: filtration, cyclones, centrifugal separator

\section{HIDROCICLONE PARA PRÉ-FILTRAGEM DA ÁGUA DE IRRIGAÇÃO}

\begin{abstract}
RESUMO: A utilização de água contendo partículas sólidas em suspensão tem sido a causa de sérios problemas em sistemas de irrigação. A escolha do tipo e capacidade do sistema de filtragem é de fundamental importância para evitar aumento nos custos de operação e manutenção do sistema de irrigação. Pré-filtros, como os hidrociclones, caracterizam-se por significativo poder de separação de partículas presentes na água. Apesar de algumas referências feitas aos hidrociclones, não se dispõe no Brasil de resultados do desempenho dos mesmos, quando empregados em pré-filtragem da água utilizada nos sistemas de irrigação. Assim, um experimento compreendeu a construção e a avaliação do desempenho de quatro hidrociclones do tipo Rietema, utilizando-se suspensões de areia fina e de solo argiloso, sob diferentes diferenciais de pressão, e adotandose como critério de comparação a capacidade de vazão e o poder de separação, medidos pela eficiência total e eficiência total reduzida. O hidrociclone dotado com bocal de alimentação circular apresentou os maiores índices nos critérios de comparação, com suspensão de areia e suspensão de solo.

Palavras-chave: filtração, ciclones, separador centrífugo
\end{abstract}

\section{INTRODUCTION}

Sediments present in the water usually reduce durability of irrigation system components such as pump rotors, feeding tubes and localized irrigation pipelines. Sedimentation basins and hydrocyclones can be used to reduce the size and costs of filtering systems (Keller \& Bliesner, 1990).

The hydrocyclones are an important class of equipments destined to separation of solid-liquid suspension phases (Souza et al., 2000). An hydrocyclone consists of a conic end linked to a cylindrical body, in which there is a tangential entrance for the feeding suspension. The hydrocyclone has a tube in its upper part for the diluted suspension draining (overflow) and a hole in the under part for the concentrated suspension draining (underflow) (Figure $1 \mathrm{a}$ ). The suspension is pumped through the feeding tube and when entering the hydrocyclone it is activated by a rotational, descendent movement and tends towards the drainage point of the underflow (Flintoff et al., 1987) as shown in Figure 1b.

When the feeding suspension is introduced into the hydrocyclone, a fraction of the liquid and the higher velocity (heavier) particles are discharged through the concentrated underflow drain. The remaining liquid and the lower velocity (lighter) particles are discharged throughout the diluted overflow drain (Silva, 1989). Even though the hydrocyclone may not be separating by centrifugation, a certain amount of solids is removed with the concentrated in a rate that may be defined by the equation:

$$
R_{L}=\frac{Q_{u}\left(1-C v_{u}\right)}{Q(1-C v)}
$$




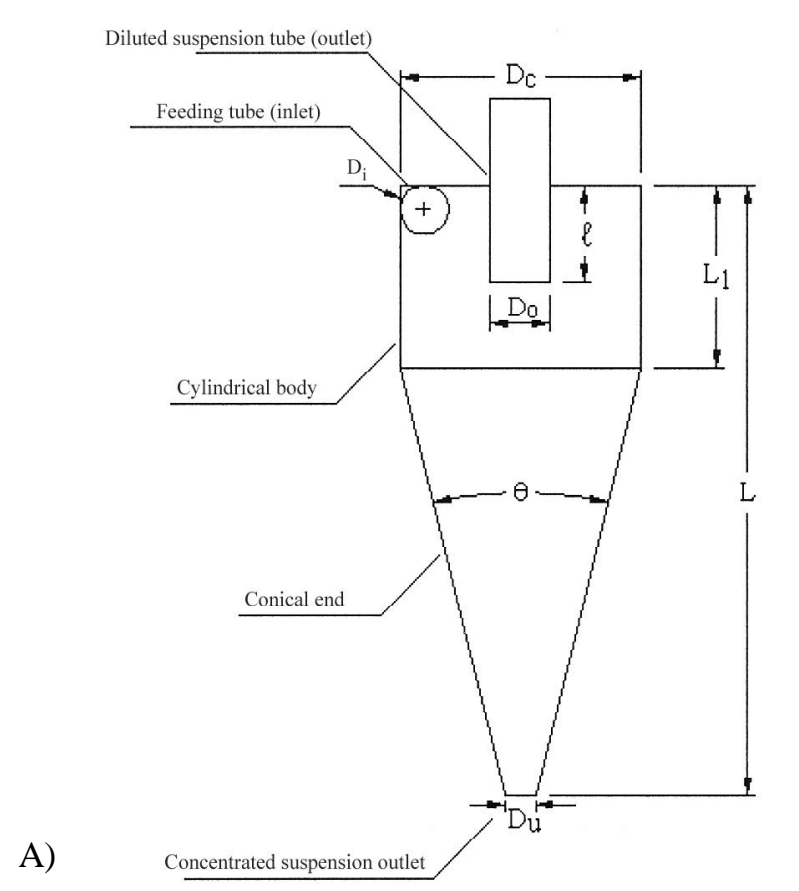

B)

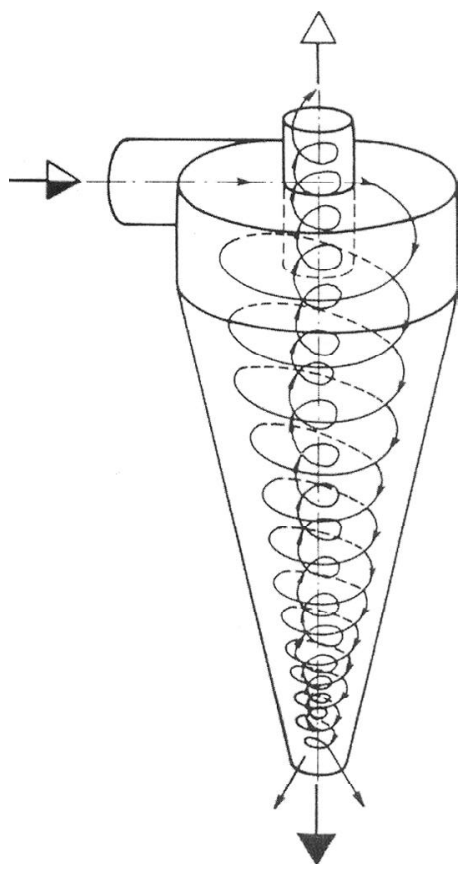

$\mathrm{D}_{\mathrm{C}}-$ Hydrocyclone diameter; $\mathrm{D}_{\mathrm{i}}-$ feeding tube diameter; $\mathrm{D}_{\mathrm{o}}$ - diluted overflow tube diameter; $\mathrm{D}_{\mathrm{U}}-$ concentrated underflow tube diameter; $\mathrm{L}-$ hydrocyclone length; $\ell$ - diluted overflow tube reentrance; $L_{1}$-hydrocyclone cylindrical part length; $\theta$ - cone angle.

Figure 1 - Diagram showing the main hydrocyclone dimensions (a) and the internal draining movement (b).

where: $\mathrm{R}_{\mathrm{L}}$ - liquid ratio, non-dimensional; $\mathrm{Q}_{\mathrm{u}}$ - concentrated suspension outflow, $\mathrm{L} \mathrm{T}^{-1} ; \mathrm{Q}$ - feeding suspension outflow, $\mathrm{L}^{3} \mathrm{~T}^{-1} ; \mathrm{Cv}_{\mathrm{u}}$ - volumetric concentration of the concentrated suspension, non-dimensional; $\mathrm{Cv}$ - volumetric concentration of the feeding suspension, non-dimensional (Silva, 1989).

The total or global efficiency is defined as the ratio between the concentrated suspension solid mass outflow and the feeding suspension solid mass outflow:

$$
E_{T}=\frac{W s_{u}}{W s}
$$

where: $\mathrm{E}_{\mathrm{T}}$ - total efficiency, non-dimensional; Ws - feeding suspension solid mass flow, $\mathrm{M} \mathrm{T}^{-1} ; \mathrm{Ws}_{\mathrm{u}}$ - concentrated suspension solid mass flow, $\mathrm{M} \mathrm{T}^{-1}$.

The reduced total efficiency is calculated by subtracting the "dead flow" contribution, thus resulting in the hydrocyclone actual performance, which has been calculated by the expression:

$$
E_{T}^{\prime}=\frac{E_{T}-R_{L}}{1-R_{L}}
$$

where: $\mathrm{E}_{\mathrm{T}}$ - reduced total efficiency, non-dimensional; $\mathrm{E}_{\mathrm{T}}$ - total efficiency, non-dimensional; $\mathrm{R}_{\mathrm{L}}$ - liquid ratio, non-dimensional (Kelsall, 1953).

This work aimed to construct and evaluate four hydrocyclones with equal dimensions, but varying the form and dimension of the feeding tubes, operating with sand and soil suspensions, in order to obtain best performance parameters and efficiency on the removal of solid particles present in the water.

\section{MATERIAL AND METHODS}

\section{Hydrocyclone assembly}

Four $50 \mathrm{~mm}$-diameter hydrocyclones were assembled for the experiment. Equipment dimensions followed recommendations of Rietema (1961), differing only regarding the shape and dimensions of the feeding tube. The hydrocyclone with circular-end feeding tube, Hydrocyclone I, the first to be dimensioned, had 13.99 $\mathrm{mm}$ internal diameter. The other three hydrocyclones were assembled with rectangular-end feeding tubes with different shapes and sizes (Table 1). For the circular-end feeding tube, the inflow rate established was equal to $2 \mathrm{~m} \mathrm{~s}^{-1}$, and the outflow, defined by the continuity equation, was $0.31 \mathrm{~L} \mathrm{~s}^{-1}$. Dimensions of the retangular-end feeding tube were calculated considering hydrocyclone pressure reduction of 50,100 and $150 \mathrm{kPa}$, for hydrocyclones II, III and IV, respectively, using the continuity equation and an average discharge coefficient of convergent, conical-end feeding tube equal to $90 \%$ (Neves, 1979).

The feeding tubes were assembled using 15-mm nominal diameter (ND), commercial copper tubes, and the rectangular-ends were molded with the correspondent dimensions (Table 1). 


\section{Essay material}

Fine sand and clayey-soil were used as sediment material (Kandiudalfic Eutrudox). After rinsing the fine sand, was sieved through a $1.19 \mathrm{~mm}$ screen to remove coarse particles. The soil was sieved through a $0.54 \mathrm{~mm}$ screen to remove small gravels. Density of sand and soil particles were determined by the Pycnometer (density bottle) method (Kiehl, 1979), resulting in values of $2.65 \mathrm{~g} \mathrm{~cm}^{-3}$ and $2.70 \mathrm{~g} \mathrm{~cm}^{-3}$, for sand and soil, respectively. Soil fractions were also determined according to Kiehl (1979), and the following values were found: $73.55 \%$ clay, $18.26 \%$ silt, and $8.19 \%$ sand.

\section{Experimental workbench}

The experiment was performed in a workbench, in closed circuit (Figure 2):

1) Reservoir: For the sand-water or soil-water suspensions, $500 \mathrm{~L}$ capacity.

2) Motor-pump: Centrifugal pump with discharge flow of $4,500 \mathrm{~L} \mathrm{~h}^{-1}\left(0.00125 \mathrm{~m}^{3} \mathrm{~s}^{-1}\right)$, pumping pressure of 340 $\mathrm{kPa}$, and electrical motor with 1,470.60 W (2 HP) and $3,500 \mathrm{rpm}$.

3) Flowmeter: Electromagnetic flowmeter with nominal flow of $1,000 \mathrm{~L} \mathrm{~h}^{-1}\left(0,000278 \mathrm{~m}^{3} \mathrm{~s}^{-1}\right)$.

4) Pressure sensor: The pressure-differential in the hydrocyclone was evaluated by pressure plugs installed into the feeding tube and diluted suspension, using dif- ferential-transducer pressure sensors with capacity within the range of 0 to $700 \mathrm{kPa}$ and $2.5 \%$ error for temperatures between 0 and $85^{\circ} \mathrm{C}$. When fed by a $5 \mathrm{~V}$ c/c stabilized tension, the sensor emits analogical signals varying from 0.2 to $4.7 \mathrm{~V} \mathrm{c} / \mathrm{c}$, which are transformed in pressure readings. The pressure-transducer outputs were also linked to the digital analogical converser (DAC), allowing monitoring of the pressure reduction in the hydrocyclone.

5) Hydrocyclone: Sampling sites were installed close to the hydrocyclone, in the feeding tube (a) and in the diluted suspension (b).

6) Submersible shaker: Electrical motor, $1,102.90 \mathrm{~W}$ $(1,5 \mathrm{HP})$ and 1,650 rpm, kept suspension homogeneous during samplings.

7) Microcomputer: Equipped with the software Aquidados (Vilela et al., 2001), to control the digital analogical converter by signals emitted through the computer parallel port. The software also controlled transmission of digital data to the CPU unity. Such information was processed and displayed in the video-monitor, at real time, and results were simultaneously stored in specific files, with respective reading date and time records.

\section{Experimental procedures}

Sand and soil suspensions were prepared by the addition of $20 \mathrm{~kg}$ of material, previously sieved, to 450 $\mathrm{L}$ of water, resulting in an initial sediments concentration of $44.44 \mathrm{~g} \mathrm{~L}^{-1}$.

Table 1 - Characteristics of the feeding tubes used in the hydrocyclones.

\begin{tabular}{|c|c|c|c|c|}
\hline \multirow{3}{*}{ Characteristic } & \multicolumn{4}{|c|}{ Feeding-end } \\
\hline & Circular & & Rectangular & \\
\hline & $20 \mathrm{kPa}(\mathrm{I})$ & $50 \mathrm{kPa}(\mathrm{II})$ & $100 \mathrm{kPa}(\mathrm{III})$ & $150 \mathrm{kPa}(\mathrm{IV})$ \\
\hline Internal dimensions (mm) & $d=13.99$ & $1.72 \times 20.30$ & $1.20 \times 20.81$ & $0.95 \times 21.40$ \\
\hline Section $\left(\mathrm{mm}^{2}\right)$ & 153.77 & 34.92 & 24.97 & 19.99 \\
\hline
\end{tabular}

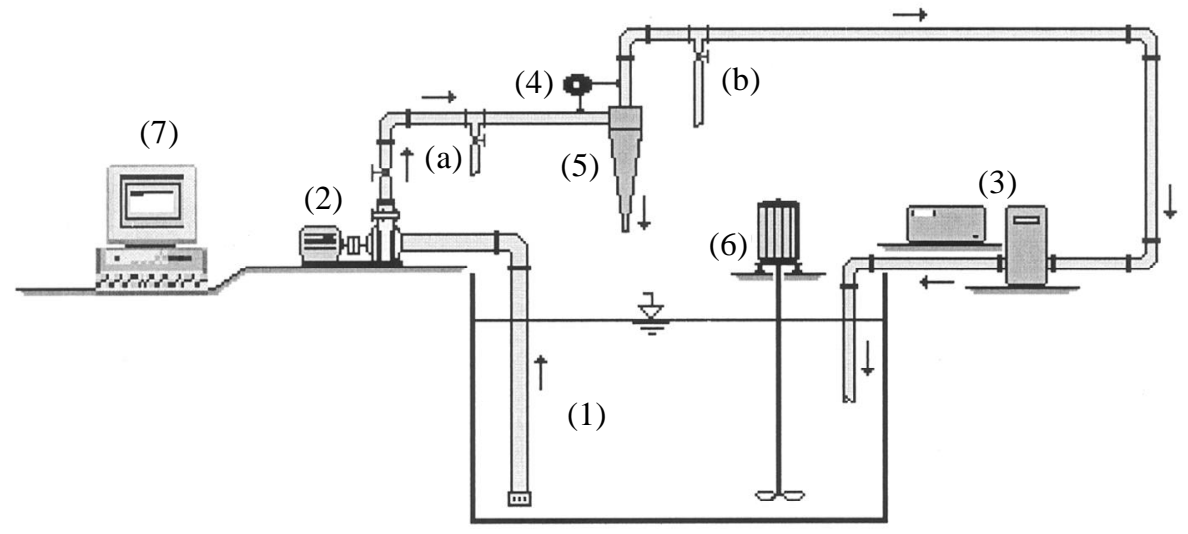

Figure 2 - Diagram of the experimental workbench and components. 
Starting of system: The workbench system was set in motion by the motor-pump; the microcomputer, the flowmeter, the pressure-sensor and the submersible shaking were then turned on. The desired pressure reduction was adjusted by the software through a gate valve installed in the pump output. Pressure differentials were: 10, 20, $30,40,50$, and $60 \mathrm{kPa}$, for the hydrocyclone I, operating with sand and soil suspensions; 20,50,100, and $150 \mathrm{kPa}$, for hydrocyclones II, III and IV, operating with soil suspension. After systems reached equilibrium, the temperature of the suspension was checked and data monitoring started. The liquid ratio (LR) was adjusted to $10 \%$ by the gate valve installed in the output of the concentrated suspension.

Data monitoring: The reading interval and data registration period were adjusted to $60 \mathrm{~s}$ in the initial display screen, and then the reading key was entered. During the flow and pressure reduction data-collecting period, aliquot samples of the concentrated suspension were taken at $30 \mathrm{~s}$ intervals and weighed, to obtain the sample mass. When the flow and pressure differential readings were finished, the feeding suspension sampling started. This procedure was repeated for each pressure differential point sampled.

Concentration measurements: The sample concentrations were determined using the gravimetric method. An aliquot sample (exact volume) was transferred to an aluminum recipient and oven dried at $110^{\circ} \mathrm{C}$ for 24 hours. After evaporation, the residue was weighed for dry matter determination and expressed as $\mathrm{g} \mathrm{L}^{-1}$.

Analysis of particle size fraction: The determination of sand and soil particle size fraction followed distinct procedures, since the replications of each sample were pooled, due to small quantity of solids collected, mainly from the feeding flow. Determination of the sand fraction was done by the sieve method and determination of the soil fraction, by the sedimentation method (Allen, 1990). A kit of ten sieves, mesh 1,000, 590, 500, 420, $297,250,149,105,74$, and $53 \mathrm{~mm}$ was used for the sand fraction analysis. The total amount of dry sand was weighed and three subsamples were taken; each subsample was set top the kit and sieved by shaking for 12 minutes. Sieves were then weighed to obtain the fraction mass $(\mathrm{X})$, correspondent to each screen meshes.

For determination of the soil particle size fraction, the method used was based on the gravimetric sedimentation, and the variation on the sediment concentration of the collected samples at determined intervals, allowed to calculate the cumulative fraction, in a mass basis, lower than a certain diameter (d), determined by the Stoke's law. The dried soil sample was weighed and transferred to a recipient with distilled water, let stand for 24 hours and stirred at 16,000 rpm for 20 minutes to disaggregate the particles. The suspension was then transferred to a $1,000-\mathrm{mL}$ graduated cylinder, distilled water was added until completing the volume, and the suspension was manually stirred for 60 seconds, using a plain-disc. The sampling period was then started: 10$\mathrm{mL}$ samples were taken, using a pipette plunged $10 \mathrm{~cm}$ into the suspension, after 10, 30, 60, 120, 180, 300, 600, 1,200 , and 1,800 seconds. Samples were transferred to small vials and oven-dried at $110^{\circ} \mathrm{C}$ for 24 hours. The dry residue was weighed in analytical balance to the nearest $0.0001 \mathrm{~g}$, for the determination of mass fraction $X$ lower than a certain Stokes diameter, using the Equation (4):

$$
X=\frac{C}{C_{o}}
$$

where: $X$ - mass fraction lower than a certain diameter, non-dimensional; $\mathrm{C}$ - sample concentration collected at time t, $\mathrm{M} \mathrm{L}^{-1} ; \mathrm{C}_{\mathrm{o}}$ - initial concentration, $\mathrm{M} \mathrm{L}^{-1}$.

At the beginning of each essay, the suspension's temperature was monitored in the graduated cylinder. The correspondent Stokes' diameter was calculated by Equation (5), for each defined sampling period of time, and resulted approximately in $7,8,12,17,22,27,38,54$, and $93 \mathrm{~mm}$, respectively.

$$
d s_{t k}=\left[\frac{18 \mu h}{g t\left(\rho_{s}-\rho\right)}\right]^{0,5}
$$

where: $\mathrm{ds}_{\mathrm{tk}}$ - Stokes' diameter, $\mathrm{L} ; \mathrm{m}$ - fluid absolute viscosity, $\mathrm{M} \mathrm{L}^{1 \mathrm{k}} \mathrm{T}^{-1} ; \mathrm{h}$ - pipette sampling depth, $\mathrm{L} ; \mathrm{g}-$ acceleration due to gravity, $\mathrm{L} \mathrm{T}^{-2} ; \mathrm{t}$ - sampling time interval, T; $\rho_{\mathrm{s}}-$ solid density, $\mathrm{M} \mathrm{L}^{-3} ; \rho$ - fluid density, $\mathrm{M} \mathrm{L}^{-3}$.

\section{RESULTS AND DISCUSSION}

\section{Hydrocyclones performance}

\section{Hydrocyclone I}

Mean values on hydrocyclone I performance operating with sand and soil suspension are presented in Table 2. The suspension sediment concentration varied with increasing pressure differential. It was not possible to keep the suspension homogeneous in the input flow to the centrifugal pump at the same time that the workbench dynamic conditions were altered, since the stirring velocity of submersible shaker was at the limit above which the suspension started to be ejected out of the reservoir. As no other shaker was available, the test took into account differences in suspension concentrations.

The feeding flow varied from $1,159.9 \mathrm{~L} \mathrm{~h}^{-1}$ to 2,603.6 $\mathrm{L} \mathrm{h}^{-1}$ and from $1,160.9 \mathrm{~L} \mathrm{~h}^{-1}$ to $2,534.8 \mathrm{~L} \mathrm{~h}^{-1}$, for operation with sand and soil suspension respectively. The suspension temperature remained between $21^{\circ} \mathrm{C}$ and $22^{\circ} \mathrm{C}$ during the essays. 
Table 2 - Average data of performance parameters of Hydrocyclone I operating with sand and soil suspension.

\begin{tabular}{|c|c|c|c|c|c|c|c|c|c|c|c|}
\hline \multirow{2}{*}{$\Delta \mathrm{P}(\mathrm{kPa})$} & Q & $\mathrm{Q}_{\mathrm{u}}$ & [A] & {$[\mathrm{C}]$} & $\mathrm{Cv}$ & $\mathrm{Cv}_{\mathrm{u}}$ & LR & Ws & $\mathrm{Ws}_{\mathrm{u}}$ & ET & ET' \\
\hline & \multicolumn{2}{|c|}{$\ldots-\ldots \mathrm{L} \mathrm{h}^{-1} \ldots \ldots$} & \multicolumn{2}{|c|}{$\ldots-\ldots$ g L$^{-1} \ldots$} & \multicolumn{3}{|c|}{ - } & \multicolumn{2}{|c|}{$\ldots \mathrm{kg} \mathrm{h}^{-1} \ldots \ldots$} & \multicolumn{2}{|c|}{$\ldots \ldots$} \\
\hline \multicolumn{12}{|c|}{ Sand } \\
\hline 10.80 & 1159.9 & 133.5 & 2.81 & 23.26 & 0.106 & 0.879 & 11.42 & 3.265 & 3.104 & 95.08 & 94.45 \\
\hline 22.30 & 1582.8 & 223.3 & 2.99 & 21.09 & 0.113 & 0.797 & 13.66 & 4.849 & 4.708 & 97.09 & 96.62 \\
\hline 29.50 & 1826.8 & 133.7 & 6.19 & 69.34 & 0.234 & 2.627 & 7.14 & 11.314 & 9.269 & 81.93 & 80.54 \\
\hline 40.40 & 2002.2 & 207.6 & 6.11 & 45.50 & 0.231 & 2.720 & 10.22 & 12.239 & 9.444 & 77.16 & 74.56 \\
\hline 52.00 & 2386.2 & 249.4 & 5.93 & 42.99 & 0.224 & 1.625 & 10.25 & 14.139 & 10.273 & 72.79 & 69.99 \\
\hline 62.70 & 2603.6 & 259.2 & 7.01 & 47.95 & 0.265 & 1.813 & 9.80 & 18.255 & 12.427 & 68.07 & 64.61 \\
\hline \multicolumn{12}{|c|}{ Soil } \\
\hline 11.90 & 1160.9 & 156.5 & 7.29 & 13.98 & 0.270 & 0.518 & 13.48 & 8.436 & 2.188 & 25.93 & 14.38 \\
\hline 22.60 & 1595.1 & 143.9 & 11.46 & 51.10 & 0.424 & 1.893 & 8.89 & 18.279 & 7.356 & 40.29 & 34.46 \\
\hline 29.60 & 1813.8 & 141.5 & 11.32 & 58.03 & 0.419 & 2.149 & 7.69 & 20.542 & 8.141 & 39.63 & 34.62 \\
\hline 43.50 & 2128.9 & 201.2 & 11.10 & 51.68 & 0.411 & 1.914 & 9.31 & 23.643 & 10.403 & 43.94 & 38.19 \\
\hline 51.90 & 2284.8 & 220.4 & 10.89 & 43.07 & 0.403 & 1.595 & 9.53 & 24.383 & 9.497 & 38.15 & 31.63 \\
\hline 63.60 & 2534.8 & 244.7 & 12.12 & 48.24 & 0.449 & 1.787 & 9.52 & 30.727 & 11.796 & 38.42 & 31.94 \\
\hline
\end{tabular}

$\Delta \mathrm{P}$ - pressure differential in the hydrocyclone; $\mathrm{Q}$ - feeding flow; $\mathrm{Q}_{\mathrm{u}}$ - concentrated flow; [A] - feeding solid concentration; [C] concentrated suspension solid concentration; $\mathrm{Cv}$ - feeding volumetric concentration; $\mathrm{Cv}_{\mathrm{u}}$ - concentrated volumetric concentration; LR liquid ratio; Ws - feeding solid mass flow; $\mathrm{Ws}_{\mathrm{u}}$ - concentrated solid mass flow; ET - total efficiency; ET' - reduced total efficiency.

For the sand suspension essays, the highest indices of total reduced efficiency $E T$ ' were $94.45 \%$ and $96.62 \%$, obtained for pressure differences of $10.80 \mathrm{kPa}$ and $22.30 \mathrm{kPa}$, respectively; the lowest was $64.61 \%$ for a $62.70 \mathrm{kPa}$ difference. For the soil suspension essays, $E T$ ' varied from $14.38 \%$ to $38.19 \%$ for pressure differences of $11.90 \mathrm{kPa}$ and $43.50 \mathrm{kPa}$, respectively, decreasing to $31.94 \%$ for a $63.60 \mathrm{kPa}$ pressure difference.

When operating with sand, hydrocyclone I had always higher total reduced efficiency $E T$ ' for similar pressure differences, as expected, due to the sand particle size characteristics. The average $E T^{\prime}$, for all the pressure differences, was $80.13 \%$ and $30.87 \%$ for the sand and soil tests, respectively. The hydrocyclone separation capacity depends on its size and geometry, particle size and geometry, solid concentration, inflow rate, liquid ratio and density difference between particles and fluid (Jacobs \& Penney, 1987). The highest sand suspension concentrations, for pressure differences higher than $22.30 \mathrm{kPa}$, had no effect on hydrocyclone performance. Even for higher feeding flows there was no gain in efficiency, what might be consequence of a greater turbulence into the hydrocyclone. For the soil suspension, the lower efficiencies obtained may be explained by the smaller particle sizes.

\section{Hydrocyclones II, III and IV}

Significantly lower feeding suspension concentrations in hydrocyclones II, III and IV were observed in comparison to those in hydrocyclone I, mainly for the pressure differences of $20 \mathrm{kPa}$ and $50 \mathrm{kPa}$ (Tables 3, 4 and 5), what may be explained by a lower feeding flow and, consequently, lower suspension turbulence in the reservoir, for first ones. The feeding flows observed during the tests varied from $806.5 \mathrm{~L} \mathrm{~h}^{-1}$ to $2,028.4 \mathrm{~L} \mathrm{~h}^{-1}$, 401.3 $\mathrm{L} \mathrm{h}^{-1}$ to $1,095.3 \mathrm{~L} \mathrm{~h}^{-1}$ and $322.8 \mathrm{~L} \mathrm{~h}^{-1}$ to $847.7 \mathrm{~L} \mathrm{~h}^{-1}$ for hydrocyclones II, III and IV, respectively.

The reduced total efficiencies obtained for hydrocyclones II, III and IV were similar to the hydrocyclone I, and the highest values were observed in the sand suspension test, with the following average mean values, for all pressure differentials: hydrocyclone II $52.99 \%$ and $21,45 \%$ for sand and soil suspension, respectively; hydrocyclone III $-36.69 \%$ and $17.25 \%$ for sand and soil suspension, respectively; hydrocyclone IV $34.45 \%$ and $12.66 \%$ for sand and soil suspension, respectively.

Comparing the performance of the four hydrocyclones, using $E T^{\prime}$ ' as reference, and considering a common pressure differential of $50 \mathrm{kPa}$, decreasing flows were observed for the hydrocyclones II, III and IV of $51.04 \%, 73.92 \%$ and $78.38 \%$, respectively, in relation to the hydrocyclone I. The flow reduction did not represent efficiency gains for these hydrocyclones, meaning that, at the same test conditions, the reduced total efficiency decreased $26.72 \%, 53.98 \%$ and $38.52 \%$ for the sand suspension, and $62.60 \%, 71.04 \%$ and $78.69 \%$ for the soil suspension, for hydrocyclones II, III and IV, respectively. Hydrocyclones III and IV showed feeding tube obstruction, what might be explained by the smaller feeding tube diameter (Table 1). 
Table 3 - Average data of performance parameters of Hydrocyclone II operating with sand and soil suspension.

\begin{tabular}{|c|c|c|c|c|c|c|c|c|c|c|c|}
\hline \multirow{2}{*}{$\Delta \mathrm{P}(\mathrm{kPa})$} & Q & $\mathrm{Q}_{\mathrm{u}}$ & {$[\mathrm{A}]$} & {$[\mathrm{C}]$} & $\mathrm{Cv}$ & $\mathrm{Cv}_{\mathrm{u}}$ & LR & Ws & $\mathrm{Ws}_{\mathrm{u}}$ & ET & ET' \\
\hline & \multicolumn{2}{|c|}{$\ldots-L^{-1} \ldots$} & \multicolumn{2}{|c|}{$\ldots-\ldots \mathrm{g} \mathrm{L}^{-1} \ldots \ldots$} & \multicolumn{3}{|c|}{ - } & \multicolumn{2}{|c|}{-.-- $\mathrm{kg} \mathrm{h}^{-1} \ldots$} & \multicolumn{2}{|c|}{ - } \\
\hline \multicolumn{12}{|c|}{ Sand } \\
\hline 23.90 & 806.5 & 94.5 & 0.35 & 2.08 & 0.013 & 0.079 & 11.70 & 0.281 & 0.197 & 72.73 & 69.13 \\
\hline 51.10 & 1165.0 & 155.5 & 0.91 & 3.48 & 0.034 & 0.132 & 13.30 & 1.063 & 0.541 & 57.79 & 51.29 \\
\hline 99.60 & 1621.8 & 195.3 & 5.69 & 25.92 & 0.215 & 0.980 & 12.00 & 9.244 & 5.069 & 59.99 & 54.47 \\
\hline 151.70 & 2017.0 & 250.4 & 7.95 & 30.63 & 0.301 & 1.159 & 12.30 & 16.059 & 7.222 & 44.84 & 37.08 \\
\hline \multicolumn{12}{|c|}{ Soil } \\
\hline 48.50 & 1121.9 & 203.7 & 6.94 & 10.64 & 0.257 & 0.394 & 18.23 & 7.72 & 2.157 & 27.90 & 11.83 \\
\hline 104.60 & 1667.3 & 190.7 & 14.23 & 42.03 & 0.527 & 1.556 & 11.32 & 23.758 & 8.029 & 33.88 & 25.45 \\
\hline 152.10 & 2028.4 & 195.3 & 12.30 & 46.80 & 0.456 & 1.733 & 9.50 & 24.954 & 8.509 & 33.97 & 27.08 \\
\hline
\end{tabular}

$\Delta \mathrm{P}$ - pressure differential in the hydrocyclone; $\mathrm{Q}$ - feeding flow; $\mathrm{Q}_{\mathrm{u}}$ - concentrated flow; $[\mathrm{A}]$ - feeding solid concentration; [C] concentrated suspension solid concentration; $\mathrm{Cv}$ - feeding volumetric concentration; $\mathrm{Cv}_{\mathrm{u}}$ - concentrated volumetric concentration; $\mathrm{LR}$ liquid ratio; Ws - feeding solid mass flow; $\mathrm{Ws}_{\mathrm{u}}$ - concentrated solid mass flow; ET - total efficiency; ET' - reduced total efficiency.

Table 4 - Average data of performance parameters of Hydrocyclone III operating with sand and soil suspension.

\begin{tabular}{|c|c|c|c|c|c|c|c|c|c|c|c|}
\hline \multirow{2}{*}{$\Delta \mathrm{P}(\mathrm{kPa})$} & Q & $\mathrm{Q}_{\mathrm{u}}$ & [A] & {$[\mathrm{C}]$} & $\mathrm{Cv}$ & $\mathrm{Cv}_{\mathrm{u}}$ & RL & Ws & $\mathrm{Ws}_{\mathrm{u}}$ & ET & ET $^{\prime}$ \\
\hline & \multicolumn{2}{|c|}{ - $\mathrm{L} \mathrm{h}^{-1} \ldots$} & \multicolumn{2}{|c|}{ - g L $^{-1} \cdots$} & \multicolumn{3}{|c|}{ - } & \multicolumn{2}{|c|}{$\ldots \mathrm{kg} \mathrm{h}^{-1} \ldots$} & \multicolumn{2}{|c|}{$-\ldots-\ldots$} \\
\hline \multicolumn{12}{|c|}{ Sand } \\
\hline 23.90 & 401.3 & 53.0 & 0.11 & 0.35 & 0.004 & 0.013 & 13.10 & 0.042 & 0.019 & 43.86 & 35.46 \\
\hline 54.30 & 602.9 & 92.8 & 0.18 & 0.50 & 0.007 & 0.019 & 15.40 & 0.108 & 0.046 & 42.64 & 32.21 \\
\hline 102.20 & 842.6 & 122.6 & 0.40 & 1.16 & 0.015 & 0.044 & 14.50 & 0.339 & 0.143 & 42.09 & 32.23 \\
\hline 151.10 & 1012.9 & 100.3 & 3.42 & 18.01 & 0.295 & 0.681 & 9.80 & 3.468 & 1.806 & 52.07 & 46.84 \\
\hline \multicolumn{12}{|c|}{ Soil } \\
\hline 48.90 & 615.4 & 113.1 & 7.37 & 10.05 & 0.273 & 0.372 & 18.36 & 4.491 & 1.141 & 25.84 & 9.16 \\
\hline 104.20 & 891.6 & 116.6 & 5.75 & 14.69 & 0.213 & 0.544 & 13.04 & 5.169 & 1.708 & 34.25 & 24.40 \\
\hline 152.00 & 1095.3 & 133.9 & 16.44 & 37.83 & 0.609 & 1.401 & 12.13 & 18.004 & 5.062 & 28.13 & 18.20 \\
\hline
\end{tabular}

$\Delta \mathrm{P}$ - pressure differential in the hydrocyclone; $\mathrm{Q}$ - feeding flow; $\mathrm{Q}$ - concentrated flow; $[\mathrm{A}]$ - feeding solid concentration; [C] concentrated suspension solid concentration; $\mathrm{Cv}$ - feeding volumetric concentration; $\mathrm{Cv}_{\mathrm{u}}$ - concentrated volumetric concentration; $\mathrm{RL}$ liquid ratio; Ws - feeding solid mass flow; $\mathrm{Ws}_{\mathrm{u}}$ - concentrated solid mass flow; ET - total efficiency; ET' - reduced total efficiency.

Table 5 - Average data of performance parameters of Hydrocyclone IV operating with sand and soil suspension.

\begin{tabular}{|c|c|c|c|c|c|c|c|c|c|c|c|}
\hline \multirow{2}{*}{$\Delta \mathrm{P}(\mathrm{kPa})$} & Q & $\mathrm{Q}_{\mathrm{u}}$ & {$[\mathrm{A}]$} & {$[\mathrm{C}]$} & $\mathrm{Cv}$ & $\mathrm{Cv}_{\mathrm{u}}$ & LR & Ws & $\mathrm{Ws}_{\mathrm{u}}$ & ET & ET' \\
\hline & \multicolumn{2}{|c|}{$\ldots-\mathrm{L} \mathrm{h}^{-1} \ldots \ldots$} & \multicolumn{2}{|c|}{$\ldots-\mathrm{g} \mathrm{L}^{-1} \ldots \ldots$} & \multicolumn{3}{|c|}{ - $\%$} & \multicolumn{2}{|c|}{-..-- $\mathrm{kg} \mathrm{h}^{-1} \ldots$} & \multicolumn{2}{|c|}{$\ldots$} \\
\hline \multicolumn{12}{|c|}{ Sand } \\
\hline 28.00 & 322.8 & 39.6 & 0.02 & 0.04 & 0.001 & 0.002 & 12.30 & 0.007 & 0.002 & 24.76 & 14.25 \\
\hline 54.90 & 497.6 & 51.3 & 0.35 & 1.67 & 0.013 & 0.063 & 10.30 & 0.174 & 0.086 & 49.26 & 43.03 \\
\hline 101.00 & 631.9 & 72.1 & 1.62 & 6.77 & 0.061 & 0.256 & 11.40 & 1.024 & 0.489 & 47.72 & 41.00 \\
\hline 148.80 & 829.9 & 91.5 & 11.87 & 49.60 & 0.449 & 1.875 & 10.90 & 9.848 & 4.537 & 46.07 & 39.50 \\
\hline \multicolumn{12}{|c|}{ Soil } \\
\hline 52.40 & 512.4 & 111.6 & 5.93 & 7.36 & 0.220 & 0.273 & 21.78 & 3.037 & 0.822 & 27.05 & 6.74 \\
\hline 105.50 & 652.7 & 139.9 & 8.54 & 12.86 & 0.316 & 0.476 & 21.40 & 5.571 & 1.798 & 32.28 & 13.84 \\
\hline 149.60 & 847.7 & 151.1 & 9.67 & 17.40 & 0.358 & 0.644 & 17.78 & 8.199 & 2.629 & 32.08 & 17.40 \\
\hline
\end{tabular}

$\Delta \mathrm{P}$ - pressure differential in the hydrocyclone; $\mathrm{Q}$ - feeding flow; $\mathrm{Q}_{\mathrm{u}}$ - concentrated flow; [A] - feeding solid concentration; [C] concentrated suspension solid concentration; $\mathrm{Cv}$ - feeding volumetric concentration; $\mathrm{Cv}_{\mathrm{u}}$ - concentrated volumetric concentration; $\mathrm{LR}$ liquid ratio; Ws - feeding solid mass flow; $\mathrm{Ws}_{\mathrm{u}}$ - concentrated solid mass flow; ET - total efficiency; ET' - reduced total efficiency.

\section{Total efficiency}

The reduced total efficiency excludes the "dead flow" effect present in the hydrocyclones, that is, there is a minimal separation efficiency because part of the feeding flow escapes the hydrocyclone by the concentrated duct. Such procedure allows performance analysis without taking into account the liquid ratio, which showed a variation among the tests in consequence of the particle 
separation by the centrifugal force. For practical purposes the main interest in the use of hydrocyclones as water prefiltering for irrigation, is the potential of removal of particles in suspension. Table 6 presents the average mean values for the total efficiency calculated from all the total efficiencies observed for each pressure differential used in the essays, and for the average pressure differential and the correspondent average feeding flow. Data in Table 6 represent the general behavior of each hydrocyclone, concerning separation potential power and the pressure differential necessary for best performance. In relation to the sand suspension tests, the highest efficiency value was obtained for the hydrocyclone I (82.02\%), followed by lower values of $58.84 \%, 45.17 \%$, and $41.95 \%$, obtained for hydrocyclones II, III and IV, respectively. In the soil suspension tests, the highest efficiency was also obtained for the hydrocyclone I, with reduction $1 / 3$ of the pressure differential. However, lower differences in efficiency with the other three hydrocyclones were observed.

The increasing pressure differential in the rectangular-end feeding tube hydrocyclones did not result in increased efficiency, but in lowering flows with consequent decreasing centrifugal forces generated in them. This evidenced the lower power of separation of these hydrocyclones when compared to the circular-end feeding tube hydrocyclone.

Although the tests were done with a high solid concentration in the suspensions, the hydrocyclones showed high performance, especially the hydrocyclone I, what demonstrates their relevance to the pre-filtering of water to be used for irrigation. Data presented in Table 6 show that, 4,732.6 $\mathrm{g}$ of sand could enter the system through irrigation during 1-hour operation without the help of a hydrocyclone; when a hydrocyclone is in operation, only 137.7 g 34.4-fold less of sand would enter the system, considering a homogeneous suspension. In another words, the irrigation system operating with the hydrocyclone I would take 34.4 hours to release the same amount of sand than released by an irrigation system in 1-hour without the hydrocyclone I. Test analysis with soil suspensions. Shows that 23,630.8 g and 13,248.1 g (1.78fold less soil sediment) would be released from the system without and with the use of hydrocyclone I, respectively.
Table 6 - Mean values of total efficiency, pressure differential and feeding flow calculated from the results of all tests made with the hydrocyclones operating with the sand and soil suspensions.

\begin{tabular}{lccrc}
\hline Hydrocyclone & Suspension & $\overline{\mathrm{ET}} \%$ & $\overline{\Delta \mathrm{P}} \mathrm{kPa}$ & $\mathrm{Q}\left(\mathrm{L} \mathrm{h}^{-1}\right)$ \\
\hline \multirow{2}{*}{$\mathrm{I}$} & sand & 82.02 & 36.28 & 1926.92 \\
& soil & 37.73 & 37.23 & 1919.72 \\
\hline \multirow{2}{*}{ II } & sand & 58.84 & 81.58 & 1402.58 \\
& soil & 31.92 & 101.73 & 1605.87 \\
\hline \multirow{2}{*}{ III } & sand & 45.17 & 82.88 & 714.93 \\
& soil & 29.41 & 101.70 & 867.43 \\
\hline \multirow{2}{*}{ IV } & sand & 41.95 & 83.18 & 570.55 \\
& soil & 30.47 & 102.50 & 670.93 \\
\hline
\end{tabular}

$\overline{\mathrm{ET}}$ - average total efficiency of all tests; $\overline{\Delta \mathrm{P}}$ - average pressure differential of all tests; $\mathrm{Q}$ - feeding flow.

\section{REFERENCES}

ALLEN, T. Particle size measurement. 4.ed. London: Chapman \& Hall, 1990. 832p.

FLINTOFF, B.C.; PLITT, L.R.; TURAK, A.A. Cyclone modeling: a review of present technology. Canadian Institute of Mining, Metallurgy and Petroleum Bulletin, v.80, p.39-50, 1987.

JACOBS, L.J.; PENNEY, W.R. Phase segregation. In: ROUSSEAU, R.W. (Ed.) Handbook of separation process technology. New York: WileyInterscience, 1987. cap.3, p.160-218.

KELLER, J.; BLIESNER, R.D. Sprinkle and trickle irrigation. New York: Chapman \& Hall, 1990. 625p.

KELSALL, D.F. A further study of the hydraulic cyclone. Chemical Engineering Science, v.2, p.254-272, 1953.

KIEHL, E.J. Manual de edafologia: relações solo-planta. São Paulo: Ed. Agronômica Ceres, 1979. 264p.

NEVES, E.T. Curso de hidráulica. 6.ed. Porto Alegre: Editora Globo, 1979. $577 \mathrm{p}$

RIETEMA, K. Performance and design of hydrocyclones I, II, III, IV. Chemical Engineering Science, v.15, p.298-325, 1961.

SILVA, M.A.P. da. Hidrociclones de Bradley: dimensionamento e análise de desempenho. Rio de Janeiro: UFRJ, 1989. 81p. (Dissertação Mestrado).

SOUZA, F.J.; VIEIRA, L.G.M.; DAMASCENO, J.J.R.; BARROZO, M.A.S. Analysis of the influence of the filtering medium on the behaviour of the filtering hydrocyclones. Powder Technology, v.117, p.259-267, 2000

VILELA, L.A.A.; GERVÁSIO, E.S.; SOCCOL, O.J.; BOTREL, T.A. Sistema para aquisição de dados de pressão e vazão usando microcomputador. Revista Brasileira de Agrocomputação, v.1, p.25$30,2001$.

Received January 23, 2003

Accepted February 12, 2004 